\title{
Recovery of different waste vegetable oils for biodiesel production: A pilot experience in Bahia State, Brazil
}

\author{
Ednildo Andrade Torres ${ }^{\mathrm{a}}$, Gilberto S. Cerqueira ${ }^{\mathrm{b}}$, Tiago. M. Ferrer ${ }^{\mathrm{b}}$, Cristina M. Quintella ${ }^{\mathrm{b}}$, \\ Massimo Raboni ${ }^{c}$, Vincenzo Torretta ${ }^{\mathrm{c}, *}$, Giordano Urbini $^{\mathrm{c}}$ \\ ${ }^{a}$ Escola Politecnica, UFBA-Universidade Federal da Bahia, Salvador, Bahia, Brazil \\ ${ }^{\mathrm{b}}$ Institute of Chemistry, UFBA-Universidade Federal da Bahia, Salvador, Bahia, Brazil \\ ${ }^{\mathrm{c}}$ Department of Science and High Technology, Insubria University of Varese, Via G.B. Vico, 46, I-21100 Varese, Italy
}

\section{A R T I C L E I N F O}

\section{Article history:}

Received 30 November 2012

Accepted 29 July 2013

Available online 27 August 2013

\section{Keywords:}

Biodiesel

Energy production

Pilot plant

Waste oils

\begin{abstract}
A B S T R A C T
In Brazil, and mainly in the State of Bahia, crude vegetable oils are widely used in the preparation of food. Street stalls, restaurants and canteens make a great use of palm oil and soybean oil. There is also some use of castor oil, which is widely cultivated in the Sertão Region (within the State of Bahia), and widely applied in industry. This massive use in food preparation leads to a huge amount of waste oil of different types, which needs either to be properly disposed of, or recovered. At the Laboratorio Energia e Gas-LEN (Energy \& Gas lab.) of the Universidade Federal da Bahia, a cycle of experiments were carried out to evaluate the recovery of waste oils for biodiesel production. The experiences were carried out on a laboratory scale and, in a semi-industrial pilot plant using waste oils of different qualities. In the transesterification process, applied waste vegetable oils were reacted with methanol with the support of a basic catalyst, such as $\mathrm{NaOH}$ or $\mathrm{KOH}$. The conversion rate settled at between $81 \%$ and $85 \%$ (in weight). The most suitable molar ratio of waste oils to alcohol was $1: 6$, and the amount of catalyst required was $0.5 \%$ (of the weight of the incoming oil), in the case of $\mathrm{NaOH}$, and $1 \%$, in case of $\mathrm{KOH}$.

The quality of the biodiesel produced was tested to determine the final product quality. The parameters analyzed were the acid value, kinematic viscosity, monoglycerides, diglycerides, triglycerides, free glycerine, total glycerine, clearness; the conversion yield of the process was also evaluated.
\end{abstract}

(c) 2013 Elsevier Ltd. All rights reserved.

\section{Introduction}

The increasing production of waste frying oils (WFOs) from household and industrial sources is a growing problem in Brazil and throughout the world. This residue is regularly poured down the drains, which results in problems for sewerage and wastewater treatment plants (Vaccari et al., 2012). In some cases, it is introduced into the food chain, through animal feed, and thus becomes a potential cause of human health problems (Felizardo et al., 2006; Costa Neto et al., 2000). As an interesting alternative, WFOs could be converted into biodiesel, a renewable fuel for diesel engines, instead of mineral diesel. This solution is widely supported by Brazilian Governement inside his wide program (Biodiesel Production and Use Program, BPUP) in favor of renewable energies and specifically by the biodiesel program mainly addressed for energy selfsustaining of isolated rural communities (Langevin, 2010).

As it comes from a renewable source, biodiesel has many environmental advantages over mineral diesel. Furthermore, its use

\footnotetext{
* Corresponding author. Tel.: +39 0332 218782; fax: +39 0332218779 .

E-mail address: vincenzo.torretta@uninsubria.it (V. Torretta).
}

leads to a reduced danger of fire due to its high flash point (commonly between $100^{\circ} \mathrm{C}$ and $210^{\circ} \mathrm{C}$ ), while the flash point of mineral diesel is remarkably low, around $50{ }^{\circ} \mathrm{C}$ (Sharma et al., 2008).

Biodiesel is normally produced by a catalyzed transesterification process of a vegetable oil or animal fat, such as beef tallow (Sabudak and Yildiz, 2010), with a short-chain alcohol as the reagent. There are more than 350 species of oil crop in the world: castor, rapeseed, sunflower, soybean, palm, etc. Only some of these are conveniently used for biodiesel production due to the specific productivity and the local climate; in the USA, soybean is the most commonly used, while in Europe, rapeseed is the favorite. In Brazil, at present, industrial production primarily uses soybean and palm oil. In general, the current trend of using monocultures for biofuels production should be corrected, and Brazil might benefit particularly, due to its vast biodiversity.

The most commonly used alcohol is methanol, which is normally obtained from mineral oil; ethanol is a potential alternative source that may be produced from a renewable source (i.e. sugarcane in Brazil). Catalysts are acid/basic or enzymatic, and catalysis is homogeneous or heterogeneous (Ribeiro et al., 2007). 
The choice of catalyst depends on the free fatty acid (FFA) level in the oil. The FFA concentration should not exceed a specific level, in the case of alkaline catalysis. According to some authors (Canaki and Van Gerpen, 2001), the maximum oil acidity should not exceed $3 \%$, if $6 \mathrm{mg} \mathrm{KOH} \mathrm{g}^{-1}$ of catalyst is to be used. Alkaline catalysis is also very sensitive to water content; in spite of these disadvantages, alkaline catalysis guarantees a good rate of conversion, and is quicker and less corrosive than acidic catalysis (Marchetti et al., 2007).

The main problem in processing waste oils, as opposed to fresh vegetable oils, lies in the fact that they are a sum of small quantities, each of which has a significantly different quality. This characteristic is generally considered detrimental for an acceptable level of conversion to biodiesel.

In this experience, biodiesel production effectively relied on a transesterification process of waste vegetable oil, with methanol supporting the reaction, with a basic catalyst, such as $\mathrm{NaOH}$ or $\mathrm{KOH}$. The conversion rate (in terms of weight) was between $81 \%$ and $85 \%$.

The greatest problem that arose during the production process arose because of the acidity of waste vegetable oils. The high acidity level led to a lower rate of biodiesel production (lowest production rate of $11.61 \%$, with acid value of 7.5 ) although an acidity neutralization step (with $\mathrm{KOH}$ ) was introduced in the production process.

The best processing rate was obtained with an oil/methanol ratio (in moles) of $1 / 6$, using $\mathrm{KOH}$ as the catalyst, with a proportion of $1 \%$ (in weight) of the processed oil.

\section{Materials and methods}

\subsection{The UFBA pilot plant}

The UFBA (Universidade Federal da Bahia - Federal University of Bahia) Biodiesel Group contains more than sixty people, including lecturers, technicians, researchers, students, Ph.D. fellows, and others, who work to develop a variety of projects, together with Brazilian Promotion Agencies, Companies (Petrobras, IBR, BomBrasil) and other Brazilian and foreign Universities, such as the Dept. of Science and High Technology at the University of Insubria (Italy).

In collaboration with the University of Insubria, these researchers developed a multi-year research program on biodiesel production, which investigated the whole production chain, gaining a great deal of experience in all of the different phases of production: transesterification reactions, both on a lab scale and in the pilot plant; chemical analysis; the study of chemical reactions and the characterization of vehicle emissions.

Thus, the Federal university is contributing to scaling up new approaches that have been developed for the preparation of biodiesel, the testing of new fuels and blends in engines (stationary and vehicle), the evaluation of the consumption of the engine and its components, the study of photo-chemical reactions that involve the exhaust gases, the analysis and definition of the specifications of raw materials, blends and by-products, by means of new ways of exploiting the reuse of glycerine.

A pilot (semi-industrial) plant for biodiesel production was installed on the site of the university (built at the end of the 1990's, with a contribution from the University of Insubria, and financial support from the Region of Lombardy, Italy). The plant is designed to produce 10,000 cubic meters of biodiesel/year from animal fats and waste oils collected from different sites. Fig. 1 is a view of the biodiesel production plant.

The main steps for producing biodiesel in the plant are as follows: oil treatment (neutralization and thermal drying), alcoholcatalyst mixing, transesterification reaction, decanting, glycerine

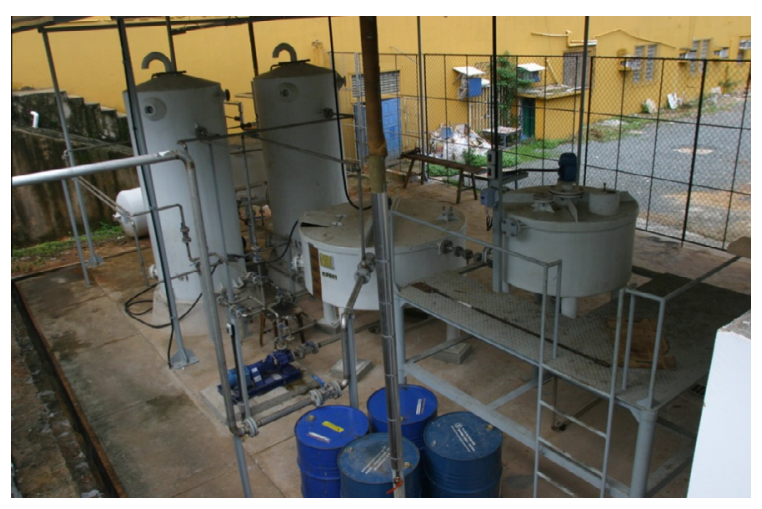

Fig. 1. View of the UFBA biodiesel plant, capacity $10,000,000 \mathrm{~L} \mathrm{year}^{-1}$.

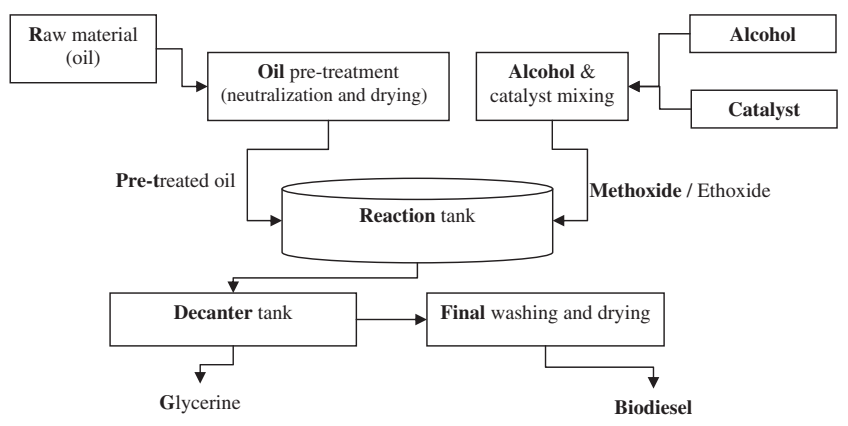

Fig. 2. Flow-chart of pilot plant for biodiesel production.

separation, biodiesel washing and drying. The process is shown in Fig. 2.

\subsection{Lab tests for biodiesel production}

Prior to the pilot-scale application, biodiesel production was tested on a lab scale. Once the lab test had produced some biodiesel, the product was tested to confirm that it complied with the Brazilian technical standards established by the ANP (Agencia National do Petroleo, Gas natural e Biocombustiveis). After this phase, the optimized process was replicated in the pilot plant.

The fuel produced was tested at the Energy and Gas Lab (LEN) of the Federal University, in accordance with ANP-approved methods.

Fourteen biodiesel production tests (on different oil samples) were developed on a lab scale, using three different molar ratios for oil to alcohol: $1-4 ; 1-5 ; 1-6$. $\mathrm{KOH}$ and $\mathrm{NaOH}$ were used as catalysts, with concentrations of $1 \%$ and $0.5 \%$, respectively.

\subsection{Analytic parameter for biodiesel quality and methods}

The parameters analyzed for evaluating biodiesel quality, and the related methods were as follows:

- Appearance (-).

- Specific mass @ $20^{\circ} \mathrm{C}$ (NBR 7148).

- Kinematic viscosity @ $40{ }^{\circ} \mathrm{C}$ (ABNT 10441).

- Flash point (ABNT 14598).

- Sulfated ash (ABNT 9842).

- Total acidity (ABNT 14448).

- Free glycerol (EN 14105).

- Total glycerol (EN 14105).

- Monoglycerides (EN 14105).

- Diglycerides (EN 14105).

- Triglycerides (EN 14105). 


\section{Results and discussion}

\subsection{Lab tests for biodiesel production}

The results obtained with the laboratory tests are shown in Tables $1-3$, below.

Several tests showed that the maximum acceptable oil acid value for producing methyl esters, in accordance with ANP standards, is $3 \mathrm{mg} \mathrm{KOH} \mathrm{g}^{-1}$ of oil. Values exceeding this limit lead to saponification reactions, which compromise the biodiesel production. In these cases, it was necessary to include a neutralization stage beforehand, to remove the undesired excess acidity.

Tables 1-3 show that the maximum registered oil acid value was $2.5 \mathrm{mg} \mathrm{KOH} \mathrm{g}^{-1}$ oil, while the mean was $1.79 \mathrm{mg} \mathrm{KOH} \mathrm{g}^{-1}$ oil. These values may be considered satisfactory, as they are in line with ANP standards, and at the same time, allow minimizing the rate of saponification in the transesterification reaction.

These tables also highlight the acid value of the biodiesel produced. ANP Resolution No. 042 specifies that the maximum acceptable value for biodiesel is $0.8 \mathrm{mg} \mathrm{KOH} \mathrm{g}^{-1}$ of oil. The results show that, in just two cases, the recorded values were close to the upper limit, but complied with the ANP standard, with a mean value of $0.49 \mathrm{mg} \mathrm{KOH} \mathrm{g}^{-1}$.

The kinematic viscosity was checked using a specific device, at a temperature of $40^{\circ} \mathrm{C}$, as required by ANP technical specifications, and expressed in cSt. Table 2 shows how, in three cases, the viscosity values were slightly over the limit of $7 \mathrm{cSt}$, set by the standards. This value is the maximum allowed to maintain a lubrication level that will not damage the engine. The three samples with results above the threshold were obtained with the 1:5 ratio of oil to alcohol, and two of them came from oils with very high acid values and were produced with $\mathrm{NaOH}$ as the catalyst.

From chromatographic analysis, tests with the molar ratio 1:6 show levels of mono- and diglycerides that fully comply with the

Table 1

Test results (oil/alcohol molar ratio 1:6).

\begin{tabular}{|c|c|c|c|c|c|}
\hline Parameters & Test 1 & Test 2 & Test 3 & Test 4 & Test 5 \\
\hline Oil acid value (mg KOH/g oil) & 1.8 & 1.5 & 1.5 & 2.5 & 1.98 \\
\hline Oil quantity (g) & 2000 & 2000 & 2000 & 2000 & 2000 \\
\hline MeOH quantity (g) & 400 & 400 & 400 & 400 & 400 \\
\hline Catalyst quantity (g) & 20 & 10 & 10 & 10 & 10 \\
\hline Biodiesel produced (\%) & 72.3 & 74.68 & 72.1 & 78.5 & \\
\hline Biodiesel density $\left(\mathrm{g} \mathrm{cm}^{-3}\right)$ & 0.88 & 0.88 & 0.88 & 0.88 & 0.88 \\
\hline Glycerine density $\left(\mathrm{g} \mathrm{cm}^{-3}\right)$ & 1.23 & 1.23 & 1.23 & 1.23 & 1.23 \\
\hline Biodiesel acid value ( $\mathrm{mg} \mathrm{KOH} / \mathrm{g}$ ) & 0.61 & 0.29 & 0.35 & 0.4775 & 0.5152 \\
\hline Kinematic viscosity, $40^{\circ} \mathrm{C}(\mathrm{cSt})$ & 4.58 & 2.16 & 5.53 & 6.02 & 6.065 \\
\hline Monoglycerides (\%) & 0.0659 & 0.0636 & 0.9318 & & \\
\hline Diglycerides (\%) & 0.0197 & 0.1117 & 0.08161 & & \\
\hline Triglycerides (\%) & 0.0772 & 0.1669 & 0.01269 & & \\
\hline
\end{tabular}

ANP limits, while the triglycerides appear to be a little over this limit (max $0.103 \%$ of total mass) in one test (test 2 ). The tests with the molar ratio of 1:5 show mono- and diglyceride values that generally comply with the standards except test 12 which gave a result over the limit for diglycerides. At the same time, in test No. 6 the triglyceride value was over the limit. With the third ratio (1:4), the results obtained (test 13 ) were satisfactory for monoglycerides and diglycerides, while the triglyceride value was over the limit.

The results show with evidence that the quality of biodiesel produced is strongly influenced by raw oils acidity as well as oil/ alcohol molar ratio and also catalyst. High oils acidity and low molar ratios can be a main cause of poor quality (high biodiesel acidity; high content of diglycerides and triglycerides; high kinematic viscosity).

A high mono-, di- or triglyceride value in biodiesel may lead to complications due to the deposition of fats, clogging of the filter, and deterioration of the fuel.

\subsection{Biodiesel production in a pilot plant}

On a pilot-plant scale, six batch tests were done, using a 1:4 oil to alcohol molar ratio, waste oil and fats; $\mathrm{KOH}$ and $\mathrm{NaOH}$ were used as catalysts, in proportions of $1 \%$ and $0.5 \%$, respectively, of the starting quantity of oil.

Table 4 shows that, in only one case, the recorded glycerine production was high, considering that in industrial practice, the maximum convenience level is of the order of $14-18 \%$, which corresponds to a minimum biodiesel production value of $85-82 \%$. The resulting acid value should be considered optimum, with a mean value of $0.4924 \mathrm{mg} \mathrm{KOH} \mathrm{g}^{-1}$, with the exception of test 1 , which had a value of $1.16 \mathrm{mg} \mathrm{KOH} \mathrm{g}^{-1}$, which was above the maximum allowed.

Table 3

Test results (oil/alcohol molar ratio 1:4).

\begin{tabular}{lll}
\hline Parameters & Test 13 & Test 14 \\
\hline Oil acid value (mg KOH/g oil) & 1.8 & 1.7 \\
Oil quantity (g) & 2000 & 2000 \\
MeOH quantity (g) & 300 & 300 \\
Catalyst quantity (g) & 20 & 20 \\
Biodiesel produced (\%) & 79.6 & 81.3 \\
Biodiesel density $\left(\mathrm{g} \mathrm{cm}^{-3}\right)$ & 0.88 & 0.88 \\
Glycerine density $\left(\mathrm{g} \mathrm{cm}^{-3}\right)$ & 1.23 & 1.23 \\
Biodiesel acid value $(\mathrm{mg} \mathrm{KOH} / \mathrm{g})_{\text {Kinematic viscosity } 40^{\circ} \mathrm{C}(\mathrm{cSt})}$ & 0.74 & 0.61 \\
Monoglycerides $(\%)$ & 5.05 & 5.76 \\
Diglycerides $(\%)$ & 0.0615 & \\
Triglycerides (\%) & 0.0002 & \\
\hline
\end{tabular}

Table 2

Test results (oil/alcohol molar ratio 1:5).

\begin{tabular}{|c|c|c|c|c|c|c|c|}
\hline Parameters & Test 6 & Test 7 & Test 8 & Test 9 & Test 10 & Test11 & Test 12 \\
\hline Oil acid value (mg $\mathrm{KOH} / \mathrm{g}$ oil) & 1.7 & 1.7 & 1.7 & 1.7 & 1.4 & - & 2.32 \\
\hline Oil quantity $(\mathrm{g})$ & 2000 & 2000 & 2000 & 2000 & 2,000 & 2000 & 2000 \\
\hline MeOH quantity (g) & 350 & 350 & 350 & 350 & 350 & 350 & 350 \\
\hline Catalyst quantity (g) & 20 & 20 & 10 & 5 & 5 & 10 & 10 \\
\hline Biodiesel produced (\%) & 81.6 & 76.8 & 79.0 & 60.6 & 77.3 & 67.0 & 83.98 \\
\hline Biodiesel density $\left(\mathrm{g} \mathrm{cm}^{-3}\right)$ & 0.88 & 0.88 & 0.88 & 0.88 & 0.88 & 0.88 & \\
\hline Glycerine density $\left(\mathrm{g} \mathrm{cm}^{-3}\right)$ & 1.23 & 1.23 & 1.23 & 1.23 & 1.23 & 1.23 & \\
\hline Biodiesel acid value (mg $\mathrm{KOH} / \mathrm{g}$ ) & 0.09 & 0.39 & 0.54 & 0.47 & 0.55 & 0.49 & 0.758 \\
\hline Kinematic viscosity $40^{\circ} \mathrm{C}(\mathrm{cSt})$ & 5.45 & 5.44 & 6.2 & 7.96 & 3.28 & 7.22 & 7.4 \\
\hline Monoglycerides (\%) & 0.0600 & 0.0634 & 0.0595 & & & & 0.0536 \\
\hline Diglycerides (\%) & 0.0001 & 0.00009 & 0.0002 & & & & 0.2442 \\
\hline Triglycerides (\%) & 0.1772 & 0.04964 & 0.0951 & & & & 0.0288 \\
\hline
\end{tabular}


Table 4

Pilot scale test results.

\begin{tabular}{|c|c|c|c|c|c|c|c|}
\hline Parameter & Test 1 & Test 2 & Test 3 & Test 4 & Test 5 & Test 6 & ANP limit \\
\hline Glycerine production (\%) & 14.7 & 13.07 & 12.86 & 19.3 & 13.53 & 16.67 & \\
\hline Biodiesel production (\%) & 85.3 & 86.9 & 87.1 & 80.7 & 86.5 & 83.3 & \\
\hline Acid value (mg $\mathrm{KOH} / \mathrm{mg}$ ) & 1.16 & 0.24 & 0.375 & 0.768 & 0.43 & 0.66 & 0.8 \\
\hline K. viscosity (cSt) & 6.3 & 6.4 & 5.84 & 10.5 & 5.8 & 6.79 & 7 \\
\hline Flash point $\left({ }^{\circ} \mathrm{C}\right)$ & 176 & 170 & 170 & 180 & 180 & 180 & $>100$ \\
\hline
\end{tabular}

Table 5

Chromatographic analysis of the biodiesel produced.

\begin{tabular}{|c|c|c|c|c|c|c|c|}
\hline Parameter & Test 1 & Test 2 & Test 3 & Test 4 & Test 5 & Test 6 & ANP limit \\
\hline Monoglycerides (\%) & 0.133 & 0.088 & 0.146 & 0.211 & 0.125 & 0.127 & 0.255 \\
\hline Diglycerides (\%) & 0.066 & 0.038 & 0.040 & 0.060 & 0.060 & 0.088 & 0.146 \\
\hline Triglycerides (\%) & 0.112 & 0.077 & 0.048 & 0.586 & 0.189 & 0.255 & 0.103 \\
\hline
\end{tabular}

Table 4 shows that, in two cases (tests 1 and 6), the glycerine value was slightly higher than the limit considered as acceptable, while in only one case was recorded significantly high (test 4). The resulting acid value should be considered optimum, with a mean value of $0.4924 \mathrm{mg} \mathrm{KOH} \mathrm{g}^{-1}$, with the exception of test 1 , which had a value of $1.16 \mathrm{mg} \mathrm{KOH} \mathrm{g}^{-1}$, which was above the maximum allowed.

The kinematic viscosity @ $40^{\circ} \mathrm{C}$ was over the limit (7 cSt) in only test 4 , where a value of $10.5 \mathrm{cSt}$ was recorded, and the mean value was $6.226 \mathrm{cSt}$. Regarding the flash point, all tests gave acceptable results, as in all cases, the values recorded were over $100{ }^{\circ} \mathrm{C}$, with a mean of $176^{\circ} \mathrm{C}$.

Chromatographic analysis (Table 5) shows optimum values for mono- and diglycerides, but unacceptable results were obtained for triglycerides, because all the values were above the ANP limits, with the exception of tests 2 and 3 . The recorded mean value was $0.211557 \%$. A high free fatty acid value is the symptom of an incomplete reaction, because almost all the triglycerides have to be esterified, leaving a maximum of $0.103 \%$ of triglycerides unreacted. As mentioned above, a high FFA level may even lead to engine damage, clogging of the filter and deterioration of the fuel.

Table 6 shows the results of tests 2 and 3, which complied fully with 042/ANP standards.

As mentioned, all the tests carried out by the UFBA pilot plant used waste oils and fats collected from hospitals, restaurants, street food stalls and hotels in the Bahia region, processed with methanol (1:4 oil to alcohol molar ratio), and with $\mathrm{KOH}$, and alternatively $\mathrm{NaOH}$ as catalysts. $\mathrm{KOH}$ was used in tests 1 and 2, $\mathrm{NaOH}$ in test 3 . Tests 2 and 3 obtained results that complied fully with the ANP standard.

As a comment, the results obtained by the pilot plant experience are not fully satisfactory. The poor quality of the biodiesel produced in some tests can reasonably be ascribed to the high acidity level of crude vegetable oil and to the molar ratio oil/ alcohol.

Table 6

Results of tests that complied fully with ANP limits.

\begin{tabular}{llll}
\hline Parameter & Test 2 & Test 3 & ANP limit \\
\hline Glycerine (\%) & 13.07 & 12.86 & \\
Biodiesel (\%) & 86.9 & 87.1 & \\
Acidity index $\left(\mathrm{mg} \mathrm{KOH} \mathrm{mg}^{-1}\right)$ & 0.24 & 0.375 & 0.8 \\
K. viscosity $(\mathrm{cSt})$ & 6.4 & 5.84 & 7 \\
Flash point $\left({ }^{\circ} \mathrm{C}\right)$ & 170 & 170 & $>100$ \\
Monoglycerides (\%) & 0.088 & 0.146 & 0.255 \\
Diglycerides (\%) & 0.038 & 0.040 & 0.146 \\
Triglycerides (\%) & 0.077 & 0.048 & 0.103 \\
\hline
\end{tabular}

Table 7

Results of biodiesel produced with molar ratio of $1: 6$

\begin{tabular}{llll}
\hline parameters & m.u. & Limit & Result \\
\hline Clearness & - & Clean & Clean \\
Specific mass @ $20^{\circ} \mathrm{C}$ & $\mathrm{kg} / \mathrm{cm}$ & $0.85-0.9$ & 0.8927 \\
Kinematic viscosity $@ 40^{\circ} \mathrm{C}$ & $\mathrm{cSt}$ & 7 & 5.76 \\
Flash point & ${ }^{\circ} \mathrm{C}$ & $>100$ & 178 \\
Sulfated ash & $\%$ mass & 0.02 & 0.05 \\
Total acidity & mg KOH/g oil & 0.80 & 0.39 \\
Free glycerol & $\%$ mass & 0.02 & 0.0056 \\
Total glycerol & $\%$ mass & 0.38 & 0.2955 \\
Monoglycerides & $\%$ mass & - & 0.1243 \\
Diglycerides & $\%$ mass & - & 0.0736 \\
Triglycerides & $\%$ mass & - & 0.0919 \\
\hline
\end{tabular}

Therefore, new tests were prepared in order to produce fully compliant biodiesel, in the UFBA pilot plant. As a preliminary step another production test, with a molar ratio of $1: 6$, was carried out, and it gave satisfactory results, as shown in Table 7 .

Looking at the values in Table 7, it is clear that all the parameters, with the exception of sulfated ash, are in accordance with ANP standards; this shows that this molar ratio (1:6) appears to be more efficient than the previous one (1:4).

This molar ratio (1:6) was then established as the operating condition for the pilot plant, and more than 4000 liters of biodiesel that complied fully with the ANP resolution was prepared and stored on the plant site.

\section{Conclusions}

The experience demonstrated that the raw material (waste oils and fats) used for biodiesel production was of sufficiently good quality, and in only a few cases, neutralization (addition of hydroxide) was required, beforehand, to reduce its acidity.

The analysis of the formation of methyl esters in the lab scale tests was done using the acid value, kinematic viscosity, monoglycerides, diglycerides, triglycerides, free glycerine, total glycerine, clearness and conversion yield.

The lab tests showed how the quantity of glycerine separated during the decanting phase had a notable influence on the final biofuel yield; that is to say, decanting is a critical stage in the production process.

According also to the lab tests, the most suitable molar ratio of waste oils to alcohol was 1:6, and the amount of catalyst required was $0.5 \%$, in the case of $\mathrm{NaOH}$, and $1 \%$, in case of $\mathrm{KOH}$. Both these percentages are with respect to the amount of incoming oil.

The analytical results obtained on the biodiesel produced on the pilot-scale agreed with the lab-scale tests. The biodiesel produced 
proved to be in line with technical specifications and to be suitable for running diesel engines.

As found on the lab scale, the biodiesel produced by the pilot plant contained approximately $90 \%$ methyl esters, and the smaller the amount of glycerine formed, the bigger the ester yield. This confirms that the removal of glycerine is critical in the production process.

\section{Acknowledgements}

The authors wish to thank the Region of Lombardy, Italy, for their generous contribution to this project.

\section{References}

Canaki, M., Van Gerpen, J., 2001. Biodiesel production from oils and fats with high free fatty acids. Trans. Am .Soc. Agric. Eng. 44, 1429-1436.
Costa Neto, P.R., Rossi, L., Zagonel, G., Ramos, L., 2000. Produção de Biocombustível Alternativo aoÓleo Diesel Através da Transesterificação de Óleo de SojaUsadoemFrituras. Quim. Nova. 23, 531-537.

Felizardo, P., NeivaCorreiaM, J., Raposo, I., Mendes, J.F., Berkemeier, R., Bordado, J.M. 2006. Production of biodiesel from waste frying oils. Waste Manage. 26 (5), 487-494.

Langevin, M.S., 2010. Tre Brazilian biodiesel program. J. Energy Security. <http:/ www.ensec.org/index.php?option=com_content\&view=article\&id=273: brazil ian-biodiesel-program\&catid=112:energysecuritycontent\&Itemid=367>. (accessed 04-2013.

Marchetti, J.M., Miguel, V.U., Errazu, A.F., 2007. Possible methods for biodiesel production. Renew. Sustain. Energy Rev., 1300-1311.

Ribeiro, N., Pinto, A.C., Quintella, C., Rocha, G.O., Teixeira, L.S.G., Carneiro, L.L.N. Varela, M.C., Veloso, M.C.C., Olivera, A.M.O., Torres, E.A., 2007. The role of additives for diesel and diesel blended (ethanol or biodiesel) fuels: a review. Energy Fuel, 145-151.

Sabudak, T., Yildiz, M., 2010. Biodiesel production from waste frying oils and its quality control. Waste Manage. 30 (5), 799-803.

Sharma, Y.C., Singh, B., Upadhyay, S.N., 2008. Advancements in development and characterization. Fuel 87, 2355-2373.

Vaccari, M., Torretta, V., Collivignarelli, C., 2012. Effect of improving environmental sustainability in developing countries by upgrading solid waste management techniques: a case study. Sustainability 4, 2661-2672. 